\title{
Bee health: Determining the causes affecting honeybees' productivity (Apis mellifera)
}

\author{
Verónica Olate Olave ${ }^{1}$, Mayda Verde ${ }^{1}$, Leslie Vallejos ${ }^{1}$, Leonel Perez-Raymonda ${ }^{2}$, María \\ Cortese $^{2}$, and Marnix Doorn ${ }^{1}$ \\ ${ }^{1}$ Fraunhofer Chile Research Foundation \\ ${ }^{2}$ Universidad Nacional de Rosario
}

January 11, 2021

\begin{abstract}
1. Insects are responsible for the quantity and quality of one-third of all agricultural production worldwide through pollination. The quality of the pollination service and the safety of the honey production depends on the health and nutritional condition of the hives, which, for an important part is related to management practices. 2. This study aims to identify the stressors that lead to the loss of bee health and its consequences for the productivity of the hives. Different aspects related to management practices, productivity, clinical observations related to diseases, presence of health issues in the hives or in the apiaries, to the structure of the hives, weather and infestation rates by Varroa sp. mites were measured. The information was collected during two field surveys in 53 apiaries in the Province of Santa Fe, Argentina. 3. The results show correlations among many of the management practices, health condition and productivity of the hive, with most importantly the change of the bee queen, the disinfection of the beekeeping material and the number of combs in the brood chamber. 4. Although honey production is important in the region, the hive structure was deficient and inadequate during both surveys. Due to its dependence on management by the beekeeper, this suggests that a holistic approach can improve the hive structure, increasing the honey production.
\end{abstract}

\section{Hosted file}

Main manuscript.pdf available at https://authorea.com/users/388690/articles/503462-beehealth-determining-the-causes-affecting-honeybees-productivity-apis-mellifera 
Main causes affecting honeybees' productivity (Apis mellifera)

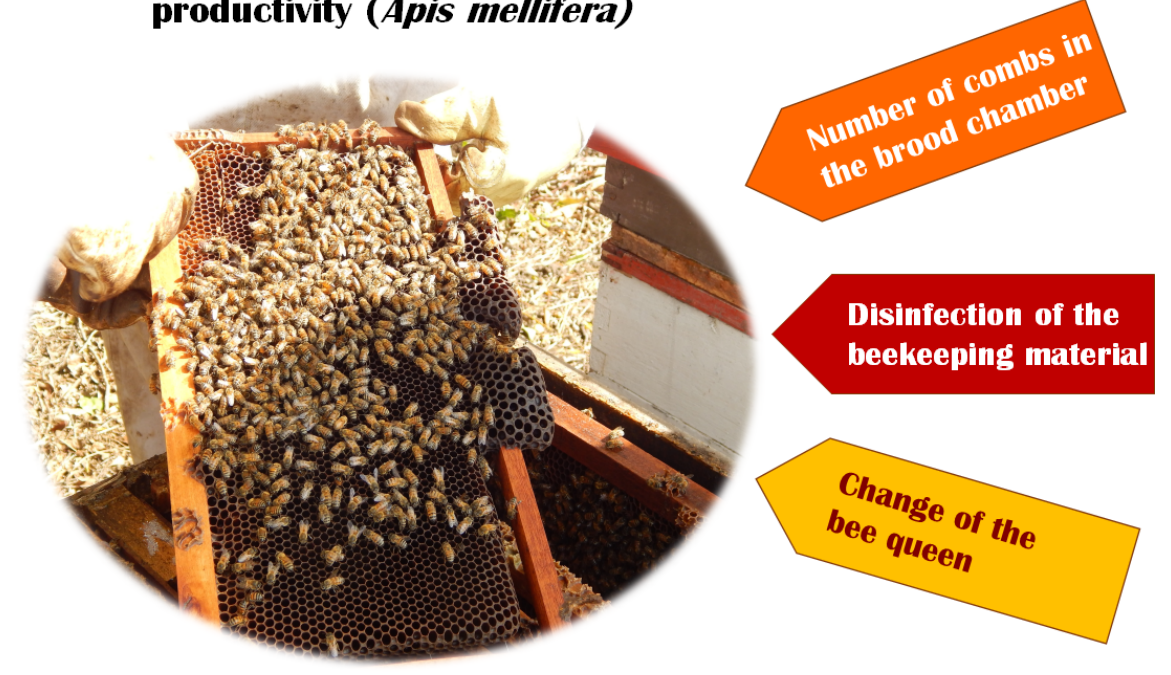

